Article

\title{
Polypharmacy in African American Adults: A National Epidemiological Study
}

\author{
Shervin Assari 1,2,*他, Hamid Helmi ${ }^{3}$ and Mohsen Bazargan 1,4 \\ 1 Department of Family Medicine, Charles R. Drew University of Medicine and Sciences, \\ Los Angeles, CA 90095, USA; mohsenbazargan@cdrewu.edu \\ 2 Center for Research on Ethnicity, Culture and Health, School of Public Health, University of Michigan, \\ Ann Arbor, MI 48109-2029, USA \\ 3 School of Medicine, Wayne State University, Detroit, MI 48202, USA; hhelmi@umich.edu \\ 4 Department of Family Medicine, University of California Los Angeles, Los Angeles, CA 90095, USA \\ * Correspondence: assari@umich.edu; Tel.: +1-734-858-8333
}

Received: 21 December 2018; Accepted: 26 March 2019; Published: 29 March 2019

check for updates

\begin{abstract}
Background: Despite the association between polypharmacy and undesired health outcomes being well established, very little is known about epidemiology of polypharmacy in the African American community. We are not aware of any nationally representative studies that have described the socioeconomic, behavioral, and health determinants of polypharmacy among African Americans. Aims: We aimed to investigate the socioeconomic and health correlates of polypharmacy in a national sample of African American adults in the US. Methods: The National Survey of American Life (NSAL, 2003-2004) included 3,570 African American adults. Gender, age, socioeconomic status (SES; education attainment, poverty index, and marital status), access to the healthcare system (health insurance and having a usual source of care), and health (self-rated health $[\mathrm{SRH}]$, chronic medical disease, and psychiatric disorders) in addition to polypharmacy $(5+$ medications $)$ as well as hyper-polypharmacy $(10+$ medications $)$ were measured. Logistic regressions were applied for statistical analysis. Results: that About 9\% and 1\% of all African American adults had polypharmacy and hyper-polypharmacy, respectively. Overall, higher age, higher SES (education and poverty index), and worse health (poor SRH, more chronic medical disease, and psychiatric disorders) were associated with polypharmacy and hyper-polypharmacy. Individuals with insurance and those with a routine place for healthcare also had higher odds of polypharmacy and hyper-polypharmacy. Conclusions: Given the health risks associated with polypharmacy, there is a need for systemic evaluation of medication use in older African Americans with multiple chronic conditions. Such policies may prevent medication errors and harmful drug interactions, however, they require effective strategies that are tailored to African Americans.
\end{abstract}

Keywords: ethnicity; race; African Americans; Blacks; medications; medication use; polypharmacy; healthcare use

\section{Background}

Despite the use of various definitions across studies [1], polypharmacy reflects a high risk of inappropriate use of medications [2,3]. Commonly defined as concomitant use of several medicines [4], polypharmacy is associated with several health threats including drug-drug interactions and reduced adherence to essential medications [5,6]. Polypharmacy is also linked to cognitive decline and unintentional falls [5,6], which are major risk factors for morbidity and mortality of older adults [7]. Polypharmacy also imposes additional economic burden on the patients, individuals, and the healthcare system, as well as on society [8]. As a result, it is essential to conduct 
national epidemiological studies to generate accurate knowledge on the prevalence and correlates of polypharmacy in the community [9].

Polypharmacy may increase the risks of hospitalization [10] and mortality $[10,11]$ in older adults. These effects are at least in part because polypharmacy increases adverse drug reactions in older individuals by $75 \%[12,13]$, which is important for the following two inter-related reasons. First, drug interactions are responsible for a major proportion of hospital admissions of older adults, and second, almost half of such hospitalizations are preventable, if we can prevent inappropriate drug interactions [14].

Polypharmacy is particularly prevalent in older adults [15-18], as they receive multiple prescribed medications [16] for their diagnosed chronic medical [1,19-21] and psychiatric [22] conditions. The prevalence of polypharmacy is also several times higher in the presence of multi-morbidities and comorbidities $[17,18]$. In many industrial countries, as the population ages, the prevalence of polypharmacy is rising too [23].

In addition to a high prevalence, older people are also more vulnerable to the adverse effects of polypharmacy due to their fragility [24]. Age-related physiological changes make older adults prone to medical complications of polypharmacy, as compared to younger individuals [24]. Race/ethnic minorities, people with low socioeconomic status (SES), and individuals with low health literacy, and cognitive dysfunction are particularly prone to adverse events due to polypharmacy [24].

For a number of reasons, polypharmacy is a major threat to African American individuals [25]. First, African Americans are less likely to receive new, most effective, and simplified medication combinations [26-30]. A lack of access to such combined/simple medication regimens likely results in their use of regimens composed of multiple, older, complex, and generic medications $[4,25]$. Such complexity of dosing regimens may increase their risk of inappropriate medication use and decrease their medication adherence [31]. From the pool of epidemiological studies that have focused on polypharmacy [32-34], very few are conducted on African Americans [4,25]. Among this limited pool of studies, we are not aware of any study with a nationally representative sample.

Research on risk factors of polypharmacy and hyper-polypharmacy in the African American community helps us identify subgroups of individuals who are at an increased risk of inappropriate medication use [35-37]. Such knowledge can inform local and national strategies that aim to eliminate racial disparities that exist in polypharmacy among older adults in the U.S. The results derived from such studies may be useful to address the unmet needs of the African American community, through first designing and then implementing and evaluating evidence-based clinical, community based, and public health programs and interventions that can specifically reduce potentially inappropriate medication use in high risk African Americans. Unfortunately, very little information exists on subgroups of African Americans have an increased risk of polypharmacy [4,25,38,39].

As mentioned earlier, only a small number of epidemiological studies have ever examined polypharmacy in African American adults [25,38,39]. From this pool, most studies have recruited a local sample, leaving a remaining need to conduct studies in nationally representative samples. On a sample of older African Americans in South Los Angeles $(n=400)$, Bazargan et al., [25] showed that $75 \%$ and $30 \%$ of all the participants were taking $5+$ (polypharmacy) and 10+ (hyper-polypharmacy) medications per day, which is above the national rates [25]. The same study estimated that about 7 of 10 participants may have inappropriate drug use. In that study, gender, number of healthcare providers, comorbid conditions, and potentially inappropriate use of medications were correlated with polypharmacy in African American older adults [25]. There is still a need to study research on the epidemiology of polypharmacy in African American adults.

Aims

Using a nationally representative sample, we aimed to investigate the demographic, socioeconomic, healthcare access, and health determinants of polypharmacy ( $5+$ medications) and hyper-polypharmacy (10 + medications) among African American adults. 


\section{Materials and Methods}

\subsection{Design and Setting}

The National Survey of American Life (NSAL 2003) [40-42] is a large national health survey of African American adults in the US. As a part of the Collaborative Psychiatric Epidemiology Surveys (CPES 2003), NSAL was supported by the National Institute of Mental Health (NIMH) [40-42].

\subsection{Ethics}

The Institutional Review Board (IRB) of the University of Michigan (UM), Ann Arbor, approved the NSAL study protocol (\# B03-00004038-R1). Participants provided informed written consent. All the individuals received a financial incentive for their time. Data were collected, restored, and analyzed in a confidential manner.

\subsection{Participants and Sampling}

The NSAL included a total number of 3570 African American adults. All participants were at least 18 years old. African Americans were drawn from large cities, other urban areas, and also rural areas. The NSAL sampling was a national household probability sample of White and Blacks/African Americans. Inclusion criteria were English speaker, non-institutionalized, resident of the U.S., and being able and willing to consent.

\subsection{Data Collection}

Approximately $82 \%$ of all the interviews were face-to-face which were performed in participants homes. The $18 \%$ remaining interviews were conducted by phone. NSAL applied Computer Assisted Personal Interviews (CAPIs) to facilitate the process of interview and enhance the data quality. The CAPI is one of the preferred methods of interviewing when the survey tool is lengthy and complex [43]. All the interviews were conducted in English language. Interviews took $100 \mathrm{~min}$ on average to complete. The response rate was about $71 \%$ for African Americans.

\subsection{Race and Ethnicity}

Race/ethnicity of the participants in the NSAL was self-identified. African Americans were Blacks who did not have ancestral ties to any Caribbean countries.

\subsection{Survey Measures and Study Variables}

\subsubsection{Demographic Characteristics}

Demographic characteristics measured for this study were age and gender. Age was treated as an interval variable, while gender was a dichotomous variable (1 male, 0 female).

\subsubsection{Socioeconomic Status}

Socioeconomic status indicators in this study included educational attainment and poverty status (income to needs ratio). Income to needs ratio, calculated based on number of the individuals in the household and household income was an interval measure, with a higher score indicating higher SES. The study defined years of schooling as a measure of SES, which was treated as an interval variable.

\subsubsection{Access to the Healthcare System}

Two indicators of access were considered: insurance status and usual place of care. Insurance status and usual place of care were both conceptualized as dichotomous variables. 


\subsubsection{Self-Rated Health (SRH)}

Participants were asked to rate their health. Responses were "excellent, very good, good, fair, or poor". The exact item read as "How would you rate your overall physical health at the present time? Would you say it is excellent, very good, good, fair or poor?" SRH can be operationalized as a dichotomous or numerical value [44-46], we treated SRH as a nominal variable. Fin our study, we compared "poor health" to any other levels (i.e., excellent, very good, good, or fair). This cutoff point is commonly used in the literature and is shown to predict mortality and health [47-53].

\subsubsection{Chronic Medical Disease (CMC)}

In this study we measured the prevalence of CMC by measuring self-reported history of doctor-diagnosed history of the following 14 chronic diseases: "diabetes, arthritis/rheumatism, peptic ulcers, cancer, hypertension, chronic liver disease, chronic kidney disease, stroke, asthma, other chronic lung diseases, atherosclerosis, sickle cell disease, heart disease, and glaucoma". Participants were asked "whether a doctor has ever told them that they have the above listed conditions". We calculated a sum score for $\mathrm{CMC}$, with a potential range of 0 to 14 , with a high score indicating a higher number of CMCs present. In this study, CMC was treated as an interval variable [54-64]. Self-reported measures of CMC are believed to be valid and reliable [64].

\subsubsection{Psychiatric Disorders}

To evaluate the endorsement of criteria for lifetime psychiatric disorders, the World Mental Health Composite International Diagnostic Interview (WMH-CIDI) was used. CIDI is based on the Diagnostic and Statistical Manual of Mental Disorders, Fourth Edition (DSM-IV). The following psychiatric disorders were assessed: "mood disorders (major depressive disorder, dysthymia, and bipolar disorders); anxiety disorders (generalized anxiety disorder, posttraumatic stress disorder, panic disorder, agoraphobia, social phobia, and obsessive compulsive disorder); substance use disorders (alcohol abuse/dependence and drug abuse/dependence); eating disorders (anorexia nervosa, bulimia nervosa, binge-eating disorder) and childhood disorders (oppositional defiant disorder, conduct disorder, separation anxiety disorder, and attention deficit/hyperactivity disorder)" [65-71]. This is a common way of treating psychiatric disorders in the literature [72,73].

\subsubsection{Polypharmacy and Hyper-Polypharmacy}

Polypharmacy was defined as taking 5+ medications [74]. Hyper-polypharmacy was defined as taking 10+ medications [74]. Participants were asked to report their medication use over the past seven days: "How many different kinds of prescription medicine have you taken during the past seven days?" The interviewees were instructed that prescription medicines are those that can be only obtained from doctors and requires doctors' written approval or prescriptions to a pharmacist. Participants were also asked to report any medicine even if it was used only once.

\subsection{Statistical Analysis}

To adjust for the NSAL complex survey design, we used Stata 15.0 (Stata Corp., College Station, TX, US) for data analysis. Taylor series technique was used for re-estimation of the NSAL design-based standard errors (SEs). All the percentages, means, associations, and $p$ values are nationally representative.

For our multivariable analyses, we applied survey logistic regressions, using sub-pop commands. In our models, polypharmacy or hyper-polypharmacy were the main dependent variables, demographic factors (age and gender), SES (educational attainment, poverty status, and marital status), access to the healthcare system (health insurance status and having a usual place of care), and health (number of chronic diseases, psychiatric disorders, and SRH) were the independent variables. 
Odds ratio (OR), standard errors (SE), and $\mathrm{p}$ values were reported. A $p$-value equal or smaller than 0.05 were considered as significant.

\section{Results}

\subsection{Descriptive Statistics}

The sample included 3570 African American adults. Table 1 describes distribution of demographic factors, SES indicators, healthcare access, health status, polypharmacy, and hyper-polypharmacy in the pooled sample and by gender.

Table 1. Descriptive results in the overall sample $(n=3570)$.

\begin{tabular}{|c|c|c|c|c|c|c|}
\hline & \multicolumn{2}{|c|}{ African Americans $(n=3570)$} & \multicolumn{2}{|c|}{ Women $(n=2299)$} & \multicolumn{2}{|c|}{$\operatorname{Men}(n=1271)$} \\
\hline & $\%(S E)$ & $95 \% C I$ & $\%(S E)$ & $95 \% C I$ & $\%(S E)$ & $95 \% C I$ \\
\hline \multicolumn{7}{|l|}{ Gender } \\
\hline Female & $44.03(0.01)$ & $42.35-45.73$ & & & & \\
\hline Male & $55.97(0.01)$ & $54.27-57.65$ & & & & \\
\hline \multicolumn{7}{|l|}{ Any Psychiatric Disorders } \\
\hline No & $60.65(0.01)$ & $58.28-62.98$ & $59.74(0.01)$ & $57.34-62.09$ & $61.82(0.02)$ & $57.35-66.10$ \\
\hline Yes & $39.35(0.01)$ & $37.02-41.72$ & $40.26(0.01)$ & $37.91-42.66$ & $38.18(0.02)$ & $33.90-42.65$ \\
\hline \multicolumn{7}{|l|}{ Married * } \\
\hline No & $58.22(0.01)$ & $56.07-60.34$ & $64.52(0.01)$ & $61.83-67.11$ & $50.22(0.02)$ & $46.86-53.57$ \\
\hline Yes & $41.78(0.01)$ & $39.66-43.93$ & $35.48(0.01)$ & $32.89-38.17$ & $49.78(0.02)$ & $46.43-53.14$ \\
\hline \multicolumn{7}{|l|}{ Routine Source of Care * } \\
\hline No & $13.95(0.01)$ & $12.22-15.88$ & $9.72(0.01)$ & $8.24-11.44$ & $19.32(0.01)$ & $16.47-22.53$ \\
\hline Yes & $86.05(0.01)$ & $84.12-87.78$ & $90.28(0.01)$ & $88.56-91.76$ & $80.68(0.01)$ & $77.47-83.53$ \\
\hline \multicolumn{7}{|l|}{ Insurance } \\
\hline No & $18.14(0.01)$ & $16.37-20.05$ & $17.74(0.01)$ & $15.22-20.57$ & $18.64(0.01)$ & $16.69-20.76$ \\
\hline Yes & $81.86(0.01)$ & $79.95-83.63$ & $82.26(0.01)$ & $79.43-84.78$ & $81.36(0.01)$ & $79.24-83.31$ \\
\hline \multicolumn{7}{|l|}{ Polypharmacy * } \\
\hline No & $90.68(0.01)$ & $89.59-91.68$ & $89.26(0.01)$ & $87.64-90.69$ & $92.49(0.01)$ & $90.51-94.09$ \\
\hline Yes & $9.32(0.01)$ & $8.32-10.41$ & $10.74(0.01)$ & $9.31-12.36$ & $7.51(0.01)$ & $5.91-9.49$ \\
\hline \multicolumn{7}{|l|}{ Hyper-Polypharmacy * } \\
\hline No & $98.95(0.01)$ & $98.23-99.39$ & $98.60(0.00)$ & 97.73-99.14 & $99.40(0.00)$ & 98.69-99.73 \\
\hline \multirow[t]{2}{*}{ Yes } & $1.05(0.01)$ & $0.61-1.77$ & $1.40(0.00)$ & $0.86-2.27$ & $0.60(0.00)$ & $0.27-1.31$ \\
\hline & Mean (SE) & $95 \% C I$ & Mean & $95 \% C I$ & Mean & $95 \% C I$ \\
\hline Age * & $42.04(0.53)$ & $40.96-43.13$ & $42.27(0.57)$ & $41.11-43.42$ & $41.75(0.67)$ & $40.39-43.12$ \\
\hline Education Attainment* & $12.46(0.08)$ & $12.29-12.63$ & $12.46(0.10)$ & $12.26-12.66$ & $12.46(0.12)$ & $12.23-12.70$ \\
\hline Poverty Index (High SES) & $2.65(0.09)$ & $2.46-2.84$ & $2.30(0.09)$ & $2.12-2.47$ & $3.10(0.13)$ & $2.84-3.35$ \\
\hline Number of CMC & $1.26(0.03)$ & $1.21-1.31$ & $1.40(0.03)$ & $1.34-1.47$ & $1.07(0.04)$ & $0.99-1.16$ \\
\hline
\end{tabular}

Source: The National Survey of American Life (NSAL, 2003-2004), CMC: Chronic Medical Conditions, SES: Socioeconomic Status, CI: Confidence Interval, OR: Odds Ratio, ${ }^{*} p<0.05$.

Table 1 suggests that $9.32 \%$ and $1.05 \%$ of African Americans report polypharmacy and hyper-polypharmacy, respectively. These prevalence rates were $10.74 \%$ and $1.40 \%$ for African American women and $7.51 \%$ and $0.60 \%$ for African American men.

African American men were more likely to be married and reported higher income to needs ratio $(p<0.05)$. African American women were more likely to report a usual source of care compared to African American men $(p<0.05)$. African American women reported more CMC than African American men $(p<0.05)$. Polypharmacy or hyper-polypharmacy were also more common in African American women than in African American men $(p<0.05)$.

\subsection{Determinants of Polypharmacy in the Pooled Sample}

Table 2 presents the results of logistic regression models with polypharmacy as the outcome in the pooled sample and by gender. Based on Model 1 which was in the pooled sample, age, access to the healthcare system (health insurance status and having a usual place for healthcare), and health (SRH, more chronic medical disease, and psychiatric disorders) were associated with polypharmacy. Older individuals, those with insurance, those with a routine place for healthcare, those who perceived 
their health as poor, individuals with a history of psychiatric disorder, and individuals who had more chronic medical conditions were more likely to report polypharmacy. Gender and SES (education and poverty index) were not associated with polypharmacy in the sample. (Table 2)

Table 2. Factors associated with polypharmacy in the pooled sample and by gender.

\begin{tabular}{ccccccc}
\hline & All & & Females & & Males \\
\hline & OR(SE) & $\mathbf{p}$ & OR(SE) & $\mathbf{p}$ & OR(SE) & $\mathbf{p}$ \\
\hline Gender (Female) & $1.25(0.25)$ & 0.290 & - & - & - & - \\
Age & $1.03(0.01)$ & $<0.001$ & $1.02(0.01)$ & $<0.001$ & $1.03(0.01)$ & 0.006 \\
Education Attainment & $1.13(0.10)$ & 0.180 & $1.10(0.14)$ & 0.441 & $1.18(0.14)$ & 0.160 \\
Poverty Status (High SES) & $1.05(0.03)$ & 0.124 & $1.02(0.04)$ & 0.666 & $1.07(0.05)$ & 0.132 \\
Marital Status (Married) & $0.92(0.17)$ & 0.666 & $1.08(0.25)$ & 0.751 & $0.71(0.15)$ & 0.124 \\
Insurance (Any) & $1.99(0.58)$ & 0.025 & $3.05(0.82)$ & $<0.001$ & $1.00(0.48)$ & 0.992 \\
Routine Place of Healthcare & $2.86(1.16)$ & 0.014 & $3.94(2.14)$ & 0.017 & $2.27(1.36)$ & 0.183 \\
Self-Rated Health (Poor) & $2.05(0.55)$ & 0.012 & $2.40(0.64)$ & 0.002 & $1.56(1.05)$ & 0.511 \\
Chronic Medical Conditions (n) & $1.80(0.11)$ & $<0.001$ & $1.77(0.12)$ & $<0.001$ & $1.92(0.15)$ & 0.000 \\
Lifetime Psychiatric Disorders & $1.45(0.25)$ & 0.042 & $1.49(0.30)$ & 0.050 & $1.37(0.39)$ & 0.273 \\
Intercept & $0.00(0.00)$ & $<0.001$ & $0.00(0.00)$ & $<0.001$ & $0.00(0.00)$ & $<0.001$ \\
\hline
\end{tabular}

Source: The National Survey of American Life (NSAL, 2003-2004), SES: Socioeconomic Status, SE: Standard Error, OR: Odds Ratio.

\subsection{Determinants of Polypharmacy in Males and Females}

Table 2 also shows the results of logistic regressions with polypharmacy as the outcome in males and females. In females, age, insurance, routine place of care, and all health indicators were correlated with polypharmacy. In males, however, only age and chronic medical conditions but not healthcare access, SRH, or lifetime psychiatric disorders were associated with polypharmacy. (Table 2)

\subsection{Determinants of Hyper-Polypharmacy in the Pooled Sample}

Table 3 shows the summary of the results of two logistic regression models with hyper-polypharmacy as the outcome in the pooled sample as well as by gender. Based on Model 1 which was in the pooled sample, age, gender SES (education attainment), healthcare access (usual place of care), and health (SRH and chronic medical disease) were associated with hyper-polypharmacy. Older individuals, females, those with a routine place for healthcare, those who perceived their health as poor, and individuals who had more chronic medical conditions had higher odds of hyper-polypharmacy. Insurance, poverty status, and lifetime psychiatric disorders were not associated with hyper-polypharmacy in the sample. (Table 3)

Table 3. Factors associated with hyper-polypharmacy in the pooled sample and by gender.

\begin{tabular}{ccccccc}
\hline & All & & Females & & Males \\
\hline & OR(SE) & $\mathbf{p}$ & OR(SE) & $\mathbf{p}$ & OR(SE) & $\mathbf{p}$ \\
\hline Gender (Female) & $3.10(1.06)$ & 0.002 & - & - & - & - \\
Age & $1.01(0.01)$ & 0.297 & $1.02(0.01)$ & 0.195 & $1.00(0.03)$ & 0.890 \\
Education Attainment & $1.53(0.33)$ & 0.050 & $1.38(0.25)$ & 0.091 & $2.98(1.94)$ & 0.101 \\
Poverty Status (High SES) & $0.95(0.07)$ & 0.538 & $1.00(0.09)$ & 0.960 & $0.72(0.27)$ & 0.378 \\
Marital Status (Married) & $2.02(1.07)$ & 0.192 & $1.59(1.12)$ & 0.518 & $6.12(6.98)$ & 0.121 \\
Insurance (Any) & $3.87(4.06)$ & 0.206 & $3.66(3.81)$ & 0.223 & - & - \\
Routine Place of Healthcare & $9.71(11.55)$ & 0.064 & $6.21(7.28)$ & 0.128 & - & - \\
Self-Rated Health (Poor) & $5.82(3.10)$ & 0.002 & $3.57(1.89)$ & 0.022 & $46.38(56.20)$ & 0.003 \\
Chronic Medical Conditions (n) & $1.81(0.14)$ & $<0.001$ & $1.73(0.15)$ & $<0.001$ & $2.10(0.41)$ & 0.001 \\
Lifetime Psychiatric Disorders & $1.82(0.69)$ & 0.123 & $2.28(0.93)$ & 0.050 & $0.45(0.47)$ & 0.446 \\
Intercept & $0.00(0.00)$ & $<0.001$ & $0.00(0.00)$ & $<0.001$ & $0.00(0.00)$ & $<0.001$ \\
\hline
\end{tabular}

Source: The National Survey of American Life (NSAL, 2003-2004), SES: Socioeconomic Status, SE: Standard Error, OR: Odds Ratio. 


\subsection{Determinants of Hyper-Polypharmacy in Males and Females}

Table 3 also shows the results of two logistic regression models with hyper-polypharmacy as the outcome in males and females. In females, health indicators were all correlated with hyper-polypharmacy. In males, SRH and chronic medical disease but not lifetime psychiatric disorders were associated with hyper-polypharmacy. In neither males nor females, age, SES, and healthcare access factors were correlated with hyper-polypharmacy. (Table 3)

\section{Discussion}

We used a national sample to investigate how demographic, socioeconomic, healthcare access, and health factors shape social patterning of polypharmacy and hyper-polypharmacy among African American adults. The study also explored gender differences in this regard.

Findings suggest that age, gender, SES (education attainment), healthcare access (health insurance and having a usual place of care), and health (SRH, chronic medical disease, and psychiatric disorders) were associated with polypharmacy and hyper-polypharmacy. However, these associations differed between polypharmacy and hyper-polypharmacy as well as by gender. For example, being female was associated with hyper-polypharmacy but not with polypharmacy. Among main observed gender differences, we found that endorsing criteria for a psychiatric disorder (lifetime) was associated with polypharmacy and hyper-polypharmacy in women but not men. Similarly, women, but not men, who perceived their health to be poor were at a higher risk of polypharmacy. Among factors that were universally associated with polypharmacy and hyper-polypharmacy was number of chronic medical diseases, showing association regardless of gender and polypharmacy level.

Among demographic factors that correlate with polypharmacy is gender [75,76]. Although not all research agrees on this issue [77], some studies have documented a higher prevalence of polypharmacy for women than men [75-78]. Women are more commonly exposed to almost all types of inappropriate drug use $[75,76]$. Some studies have suggested that the association between gender and potentially inappropriate drug use is above and beyond confounders such as age, SES, and chronic disease [76]. Women better follow the prescriptions of doctors [79]. In one study, elderly women with low education were at a higher risk of polypharmacy, hyper-polypharmacy, and potential inappropriate drug use than men with low education [80]. In another study, men were at a higher risk of cardiac polypharmacy, however, women had a higher risk of non-cardiac polypharmacy [23]. Thus, most of the literature suggests that women are at a relative disadvantage compared to males when it comes to potentially inappropriate drug use.

Compared to men, women report more chronic disease [81] Women also more commonly seek healthcare for their conditions [82]. Women are also better aware of their symptoms [83] and better communicate with doctors about symptoms [84]. For males, however, healthcare utilization may be perceived as weakness [85-87], thus men have fewer diagnosed conditions than women [88]. Even when diagnosed, men show worse adherence to treatments [89]. Men also tend to delay healthcare use [90]. Women are particularly prone to be given multiple/inappropriate psychotropic drugs [75]. These differences are partially because women more easily adopt the sick role; so they recognize and accept their experiences that reflect a health problem. These are socially learned behaviors due to gendered socialization [91,92].

Age [76] is another factor commonly linked to polypharmacy. Although some of the effect of age on polypharmacy is because of number of chronic diseases, the link between age and polypharmacy in our study remained significant above and beyond chronic diseases. As individuals age, chronic diseases accumulate over time; such growing catalogue of conditions mean more pharmacological treatments prescribed for the individual [19]. As people reach their early sixties, the majority of individuals have at least two diagnosed chronic disorders that require treatment [20]; and as individuals reach their late sixties, more than $25 \%$ of the populations have three or more diagnosed chronic disease that require treatment [21]. Age of development of chronic disease is several years younger in African Americans 
compared to Whites [93], suggesting that screening for polypharmacy may be needed for middle age African Americans.

We found that higher rather than lower education is a risk factor for hyper-polypharmacy in African Americans, a link that could not be observed for polypharmacy. Among 621 older adults (aged $>$ or $=77$ years) who were selected from Swedish Panel Study of Living Conditions of the Oldest Old, a nationally representative sample of Swedish older adults, low education was a risk factor for polypharmacy. However, this association disappeared after controlling for confounders such as physical health [94]. In another study, high level of education reduced the likelihood of polypharmacy, independent of disease burden [23]. It is unclear why we found a positive rather than a negative link between education and hyper-polypharmacy in African Americans. One hypothesis is that education enhances African American population's access to healthcare, so their medical conditions are diagnosed and treated more frequently.

One of the factors linked to polypharmacy in the current study was regular place of care. Although older African American individuals are less likely than White individuals to have a "regular care provider", having a "regular place of care" may increase their risk for inappropriate use of prescribed medications [95]. Among African American older adults in Los Angeles, Bazargan showed documented number of healthcare providers as the strongest determinant of polypharmacy [25]. Thus, healthcare access influence polypharmacy, even in African Americans who are at a relative disadvantage compared to Whites regarding healthcare access.

The results may help with the design of interventions that may reduce polypharmacy in African Americans [96,97]. Bazargan showed that the prevalence of polypharmacy is higher in African American older adults compared to national norms (NHANES) [25]. A meta-analysis that systemically reviewed 25 studies on reduction of polypharmacy in older adults found that the existing programs and interventions are not efficient in reducing unnecessary polypharmacy [98], suggesting that there is a need for future research on ways that may help us achieve a reduction of inappropriate polypharmacy [98]. Thus, the next step of research is to conduct interventional studies that may discover practical solutions to reduce polypharmacy [25].

Although polypharmacy is an increasing [99] cause of morbidity and mortality among the elderly [99], we still do not have a detailed understanding of epidemiology of this problem in African Americans. We also do not have culturally acceptable evidence-based programs that can reduce inappropriate drug use in this population.

\subsection{Implications}

The findings reported here have some public health implications that can contribute to the elimination of health disparities in African Americans. To find potentially inappropriate drug use, we need to conduct a comprehensive evaluation of medications among African Americans who are older, have high SES, have multiple medical and psychiatric conditions, and have a usual source of care.

\subsection{Limitations}

The current study was not without limitations. First of all, the design of this study was cross-sectional. Thus, we cannot infer any causal associations. Future research is needed using longitudinal design. Second, our outcome was based on self-reports of number of medications. There is a need to assess medications and not rely on patients' self-reported data. Third, many relevant confounders such as health literacy and number of healthcare providers were not used in this study. We also did not fully investigate availability and usage of healthcare services, pathways to service, and type of medical and psychiatric conditions. Data should be collected on type of medication, and inappropriate medication use. The variables were also limited to individual level, we did not collect contextual and provider characteristics. Future research should investigate all potential factors that can potentially impact inappropriate drug use. The study used old data that was collected over 15 years ago. The outdated data may cause unnecessary confusion, thus there is a need for following analysis. 
The readers should be cautious with interpretation of the findings as some differences are likely to have happened over the past 15 years. Research using data from recent years may be compared with the results reported here to understand whether major changes in the correlates of polypharmacy has happened over 15 years. Despite the above limitations, the results of this study extend the existing literature on epidemiology and correlates of polypharmacy in African Americans [25,100].

Using crude data on polypharmacy might provide conflicting information for healthcare providers. Such data should be added by more nuances on inappropriate polypharmacy. Thus, the results should be regarded as preliminary. Still, our findings have the potential to serve as a foundation for other studies, for example, looking at insurance claims to corroborate medication adherence. Various sources of bias and unmeasured confounding suggest that the interpretation of the findings should be associated with caution. Although the results and conclusions are still valid, it should be noted that using various types of data collection on polypharmacy may result in conflicting information. This is another reason the results should be interpreted with caution to avoid any confusion for healthcare providers.

\subsection{Future Research}

This study only measured polypharmacy, not unnecessary medication use or harmful, unnecessary polypharmacy. Thus, future research should be conducted on inappropriate medication use. In addition, we are aware of the fact that various medical conditions differ regarding their need for medications. The type of chronic medications may also differ across races. That means, differences in types of chronic disease may result in differences between races in polypharmacy and also correlates of polypharmacy. Thus, future research should investigate the types of conditions as well. A more comprehensive analysis is needed and may provide more precise knowledge on the links between race, SES, health, and polypharmacy. It would be important to compare ethnic groups to determine if there are health inequalities leading to polypharmacy or indeed under prescribing.

\section{Conclusions}

In summary, although with some gender differences, demographic, SES, healthcare access, and health factors are associated with polypharmacy among African Americans. Given the health risks associated with polypharmacy, there is a need to comprehensively evaluate medication use to prevent medication errors and harmful drug interactions in African Americans. Such an aim requires culturally acceptable and effective interventions that can prevent inappropriate medication use and drug interactions among African Americans.

Author Contributions: S.A. designed and conducted this analysis and drafted the manuscript. H.H. and M.B. revised the paper. All authors approved the final draft.

Acknowledgments: This study was supported by the Center for Medicare and Medicaid Services (CMS) Grant 1H0CMS331621 to Charles R. Drew University of Medicine and Science (PI: M. Bazargan). Additionally, Dr. Bazargan research are supported by the NIH under Award \# R25 MD007610 (PI: M. Bazargan), 2U54MD007598 (PI: J. Vadgama), and U54 TR001627 (PIs: S. Dubinett, and R. Jenders). Shervin Assari is partially funded by the UCLA BRITE Center which is funded by the National Institute on Minority Health and Health Disparities (4P60MD006923-05; PI = Vickie Mays). The NSAL is funded by the National Institute of Mental Health, with grant U01-MH57716 (PI: James S. Jackson).

Conflicts of Interest: The authors declare no conflicts of interest.

\section{References}

1. Mortazavi, S.S.; Shati, M.; Keshtkar, A.; Malakouti, S.K.; Bazargan, M.; Assari, S. Defining polypharmacy in the elderly: A systematic review protocol. BMJ Open 2016, 6, e010989. [CrossRef] [PubMed]

2. Taylor, L.K.; Kawasumi, Y.; Bartlett, G.; Tamblyn, R. Inappropriate prescribing practices: The challenge and opportunity for patient safety. Healthc. Q. 2005, 8, 81-85. [CrossRef] [PubMed]

3. Sapkota, S.; Pudasaini, N.; Singh, C.; Sagar, G.C. Drug prescribing pattern and prescription error in elderly: A retrospective study of inpatient record. Asian J. Pharm. Clin. Res. 2011, 4, 129-132. 
4. Guthrie, B.; Makubate, B.; Hernandez-Santiago, V.; Dreischulte, T. The rising tide of polypharmacy and drug-drug interactions: Population database analysis 1995-2010. BMC Med. 2015, 13. [CrossRef] [PubMed]

5. Ziere, G.; Dieleman, J.P.; Hofman, A.; Pols, H.A.P.; van der Cammen, T.J.M.; Stricker, B.H.C. Polypharmacy and falls in the middle age and elderly population. Br. J. Clin. Pharmacol. 2006, 61, 218-223. [CrossRef] [PubMed]

6. Flaherty, J.H.; Perry, H.M.; Lynchard, G.S.; Morley, J.E. Polypharmacy and hospitalization among older home care patients. J. Gerontol. A Biol. Sci. Med. Sci. 2000, 55, M554-M559. [CrossRef]

7. Majdan, M.; Mauritz, W. Unintentional fall-related mortality in the elderly: Comparing patterns in two countries with different demographic structure. BMJ Open 2015, 5, e008672. [CrossRef]

8. Maher, R.L.; Hanlon, J.; Hajjar, E.R. Clinical consequences of polypharmacy in elderly. Expert Opin. Drug Saf. 2014, 13, 57-65. [CrossRef]

9. Hovstadius, B.; Petersson, G. Factors leading to excessive polypharmacy. Clin. Geriatr. Med. 2012, 28, $159-172$. [CrossRef]

10. Wimmer, B.C.; Bell, J.S.; Fastbom, J.; Wiese, M.D.; Johnell, K. Medication regimen complexity and number of medications as factors associated with unplanned hospitalizations in older people: A population-based cohort study. J. Gerontol. A Biol. Sci. Med. Sci. 2016, 71, 831-837. [CrossRef]

11. Wimmer, B.C.; Bell, J.S.; Fastbom, J.; Wiese, M.D.; Johnell, K. Medication regimen complexity and polypharmacy as factors associated with all-cause mortality in older people. Ann. Pharmacother. 2016, 50, 89-95. [CrossRef] [PubMed]

12. Parameswaran, N.N.; Chalmers, L.; Peterson, G.M.; Bereznicki, B.J.; Castelino, R.L.; Bereznicki, L.R. Hospitalization in older patients due to adverse drug reactions-The need for a prediction tool. Clin. Interv. Aging 2016, 11, 497-505. [CrossRef] [PubMed]

13. Byles, J.E.; Heinze, R.; Nair, B.K.; Parkinson, L. Medication use among older Australian veterans and war widows. Intern. Med. J. 2003, 33, 388-392. [CrossRef] [PubMed]

14. Chan, M.; Nicklason, F.; Vial, J.H. Adverse drug events as a cause of hospital admission in the elderly. Intern. Med. J. 2001, 31, 199-205. [CrossRef]

15. Payne, R.A.; Avery, A.J.; Duerden, M.; Saunders, C.L.; Simpson, C.R.; Abel, G.A. Prevalence of polypharmacy in a Scottish primary care population. Eur. J. Clin. Pharmacol. 2014, 70, 575-581. [CrossRef]

16. Statens Institut för folkhälsan. Healthy Ageing: A Challenge for Europe; National Institute of Public Health: Sweden, Stockholm, 2007.

17. Barnett, K.; Mercer, S.W.; Norbury, M.; Watt, G.; Wyke, S.; Guthrie, B. Epidemiology of multimorbidity and implications for health care, research, and medical education: A cross-sectional study. Lancet 2012, 380, 37-43. [CrossRef]

18. Centers for Disease Control and Prevention and The Merck Institute of Aging \& Health. The State of Aging and Health in America. 2004. Available online: https://www.cdc.gov/aging/pdf/state_of_aging_and_ health_in_america_2004.pdf (accessed on 14 June 2016).

19. Veehof, L.J.G.; Stewart, R.E.; Haaijer-Ruskamp, F.M.; Meyboom-de Jong, B. The development of polyphamacy. A longitudinal study. Fam. Pract. 2000, 17, 261-267. [CrossRef] [PubMed]

20. Pierce, M.B.; Silverwood, R.J.; Nitsch, D.; Adams, J.E.; Stephen, A.M.; Nip, W.; Macfarlane, P.; Wong, A.; Richards, M.; Hardy, R.; et al. Clinical disorders in a post war British cohort reaching retirement: Evidence from the first National Birth Cohort study. PLoS ONE 2012, 7, e44857. [CrossRef]

21. Kuh, D.; Wong, A.; Shah, I.; Moore, A.; Popham, M.; Curran, P.; Davis, D.; Sharma, N.; Richards, M.; Stafford, M.; et al. The MRC National Survey of health and development reaches age 70: Maintaining participation at older ages in a birth cohort study. Eur. J. Epidemiol. 2016, 31, 1135-1147. [CrossRef] [PubMed]

22. McIntyre, R.S.; Jerrell, J.M. Polypharmacy in children and adolescents treated for major depressive disorder: A claims database study. J. Clin. Psychiatry 2009, 70, 240-246. [CrossRef]

23. Craig, R.; Mindell, J. Health survey for England 2013; The Health and Social Care Information Centre: London, UK, 2014.

24. Bushardt, R.L.; Massey, E.B.; Simpson, T.W.; Ariail, J.C.; Simpson, K.N. Polypharmacy: misleading, but manageable. Clin. Interv. Aging 2008, 3, 383-389. [CrossRef]

25. Bazargan, M.; Smith, J.; Movassaghi, M.; Martins, D.; Yazdanshenas, H.; Salehe Mortazavi, S.; Orum, G. Polypharmacy among underserved older African American adults. J. Aging Res. 2017, 2017, 6026358. [CrossRef] [PubMed] 
26. Wang, J.; Zuckerman, I.H.; Miller, N.A.; Shaya, F.T.; Noel, J.M.; Mullins, C.D. Utilizing new prescription drugs: Disparities among non-Hispanic whites, non-Hispanic blacks, and Hispanic whites. Health Serv. Res. 2007, 42, 1499-1519. [CrossRef]

27. Schauer, D.P.; Johnston, J.A.; Moomaw, C.J.; Wess, M.; Eckman, M.H. Racial disparities in the filling of warfarin prescriptions for nonvalvular atrial fibrillation. Am. J. Med. Sci. 2007, 333, 67-73. [CrossRef] [PubMed]

28. Mark, T.L.; Axelsen, K.J.; Mucha, L.; Sadkova, Y. Racial differences in switching, augmentation, and titration of lipid-lowering agents by Medicare/Medicaid dual-eligible patients. Am. J. Manag. Care 2007, 13, S72-S79. [PubMed]

29. Wang, J.; Noel, J.M.; Zuckerman, I.H.; Miller, N.A.; Shaya, F.T.; Mullins, C.D. Disparities in access to essential new prescription drugs between non-Hispanic whites, non-Hispanic blacks, and Hispanic whites. Med. Care Res. Rev. 2006, 63, 742-763. [CrossRef] [PubMed]

30. Farley, J.F.; Cline, R.R.; Gupta, K. Racial variations in antiresorptive medication use: Results from the 2000 Medical Expenditure Panel Survey (MEPS). Osteoporos Int. 2006, 17, 395-404. [CrossRef]

31. Claxton, A.J.; Cramer, J.; Pierce, C. A systematic review of the associations between dose regimens and medication compliance. Clin. Ther. 2001, 23, 1296-1310. [CrossRef]

32. Aparasu, R.R.; Mort, J.R.; Brandt, H. Polypharmacy trends in office visits by the elderly in the United States, 1990 and 2000. Res. Soc. Adm. Pharm. 2005, 1, 446-459. [CrossRef]

33. Kim, H.-A.; Shin, J.-Y.; Kim, M.-H.; Park, B.-J. Prevalence and predictors of polypharmacy among Korean elderly. PLoS ONE 2014, 9, e98043. [CrossRef]

34. O’Dwyer, M.; Peklar, J.; McCallion, P.; McCarron, M.; Henman, M.C. Factors associated with polypharmacy and excessive polypharmacy in older people with intellectual disability differ from the general population: A cross-sectional observational nationwide study. BMJ Open 2016, 6, e010505. [CrossRef] [PubMed]

35. Turner, J.P.; Jamsen, K.M.; Shakib, S.; Singhal, N.; Prowse, R.; Bell, J.S. Polypharmacy cut-points in older people with cancer: How many medications are too many? Support Care Cancer 2016, 24, 1831-1840. [CrossRef] [PubMed]

36. Scottish Government Model of Care Polypharmacy Working Group. Polypharmacy Guidance, 2nd ed.; 2015; Available online: http:/ / www.sehd.scot.nhs.uk/publications/DC20150415polypharmacy.pdf (accessed on 1 February 2018).

37. Scott, I.A.; Hilmer, S.N.; Reeve, E.; Potter, K.; Le Couteur, D.; Rigby, D.; Gnjidic, D.; Del Mar, C.B.; Roughead, E.E.; Page, A.; et al. Reducing inappropriate polypharmacy: The process of deprescribing. JAMA Intern Med. 2015, 175, 827-834. [CrossRef] [PubMed]

38. Bazargan, M.; Smith, J.L.; King, E.O. Potentially inappropriate medication use among hypertensive older African-American adults. BMC Geriatr. 2018, 18, 238. [CrossRef]

39. Bazargan, M.; Smith, J.; Yazdanshenas, H.; Movassaghi, M.; Martins, D.; Orum, G. Non-adherence to medication regimens among older African-American adults. BMC Geriatr. 2017, 17, 163. [CrossRef]

40. Jackson, J.S.; Torres, M.; Caldwell, C.H.; Neighbors, H.W.; Nesse, R.M.; Taylor, R.J.; Trierweiler, S.J.; Williams, D.R. The National Survey of American Life: A study of racial, ethnic, and cultural influences on mental disorders and mental health. Int. J. Methods Psychiatr. Res. 2004, 13, 196-207. [CrossRef] [PubMed]

41. Jackson, J.S.; Neighbors, H.W.; Nesse, R.M.; Trierweiler, S.J.; Torres, M. Methodological innovations in the National Survey of American Life. Int. J. Methods Psychiatr. Res. 2004, 13, 289-298. [CrossRef]

42. Heeringa, S.; Wagner, J.; Torres, M.; Duan, N.; Adams, T.; Berglund, P. Sample designs and sampling methods for the Collaborative Psychiatric Epidemiology Studies (CPES). Int. J. Methods Psychiatr. Res. 2004, 13, 221-239. [CrossRef] [PubMed]

43. Leeuw, E.D.; Hox, J.; Snijkers, G. The effect of computer-assisted interviewing on data quality. A review. In Market Research and Information Technology; Blyth, B., Ed.; ESOMAR Monogaph: Amsterdam, The Netherlands, 1998; pp. 173-198.

44. Assari, S.; Lankarani, M.M.; Burgard, S. Black-white difference in long-term predictive power of self-rated health on all-cause mortality in United States. Ann. Epidemiol. 2016, 26, 106-114. [CrossRef] [PubMed]

45. Perlman, F.; Bobak, M. Determinants of self rated health and mortality in Russia-Are they the same? Int. J. Equity Health 2008, 25, 19. [CrossRef]

46. Manor, O.; Matthews, S.; Power, C. Dichotomous or categorical response? Analysing self-rated health and lifetime social class. Int. J. Epidemiol. 2000, 29, 149-157. [CrossRef] 
47. Schnittker, J.; Bacak, V. The increasing predictive validity of self-rated health. PLoS ONE 2014, 9, e84933. [CrossRef]

48. Assari, S. Psychiatric Disorders Differently Correlate with Physical Self-Rated Health across Ethnic Groups. J. Pers. Med. 2017, 7, 6. [CrossRef] [PubMed]

49. Assari, S.; Nikahd, A.; Malekahmadi, M.R.; Lankarani, M.M.; Zamanian, H. Race by Gender Group Differences in the Protective Effects of Socioeconomic Factors Against Sustained Health Problems Across Five Domains. J. Racial Ethn. Health Disparities 2016. [CrossRef] [PubMed]

50. Ambresin, G.; Chondros, P.; Dowrick, C.; Herrman, H.; Gunn, J.M. Self-rated health and long-term prognosis of depression. Ann. Fam. Med. 2014, 12, 57-65. [CrossRef] [PubMed]

51. Assari, S.; Lankarani, M.M. Does Multi-morbidity Mediate the Effect of Socioeconomics on Self-rated Health? Cross-country Differences. Int. J. Prev. Med. 2015, 6, 85. [CrossRef] [PubMed]

52. Assari, S. Self-rated Health and Mortality due to Kidney Diseases: Racial Differences in the United States. Adv. Biomed. Res. 2018, 7, 4. [CrossRef]

53. Assari, S. Gender differences in the predictive role of self-rated health on short-term risk of mortality among older adults. SAGE Open Med. 2016, 4. [CrossRef]

54. Assari, S. Number of Chronic Medical Conditions Fully Mediates the Effects of Race on Mortality; 25-Year Follow-Up of a Nationally Representative Sample of Americans. J. Racial Ethn. Health Disparities 2017, 4, 623-631. [CrossRef]

55. Assari, S. Bidirectional associations between chronic medical conditions, disability, and depressive symptoms over 25 years: Black-White differences. Int. J. Epidemiol. Res. 2016, 3, 302-317.

56. Assari, S. The Benefits of Higher Income in Protecting against Chronic Medical Conditions Are Smaller for African Americans than Whites. Healthcare 2018, 6, 2. [CrossRef] [PubMed]

57. Lankarani, M.M.; Assari, S. Association between number of comorbid medical conditions and depression among individuals with diabetes; race and ethnic variations. J. Diabetes Metab. Disord. 2015, 14, 56. [CrossRef]

58. Watkins, D.C.; Assari, S.; Johnson-Lawrence, V. Race and ethnic group differences in comorbid major depressive disorder, generalized anxiety disorder, and chronic medical conditions. J. Racial Ethn. Health Disparities 2015, 2, 385-394. [CrossRef]

59. Assari, S.; Lankarani, M.M. Chronic medical conditions and negative affect; racial variation in reciprocal associations over time. Front. Psychiatry 2016, 7, 140. [CrossRef]

60. Assari, S. Chronic medical conditions and major depressive disorder: Differential role of positive religious coping among African Americans, Caribbean Blacks and Non-Hispanic Whites. Int. J. Prev. Med. 2014, 5, 405-413. [PubMed]

61. Assari, S.; Helmi, H.; Bazargan, M. Health Insurance Coverage Better Protects Blacks than Whites against Incident Chronic Disease. Healthcare 2019, 7, 40. [CrossRef] [PubMed]

62. Assari, S. Combined racial and gender differences in the long-term predictive role of education on depressive symptoms and chronic medical conditions. J. Racial Ethn. Health Disparities 2017, 4, 385-396. [CrossRef]

63. Assari, S.; Burgard, S.; Zivin, K. Long-term reciprocal associations between depressive symptoms and number of chronic medical conditions: Longitudinal support for black-white health paradox. J. Racial Ethn. Health Disparities 2015, 2, 589-597. [CrossRef]

64. Martin, L.M.; Leff, M.; Calonge, N.; Garrett, C.; Nelson, D.E. Validation of self-reported chronic conditions and health services in a managed care population. Am. J. Prev. Med. 2000, 18, 215-218. [CrossRef]

65. Kessler, R.C.; Andrews, G.; Mroczek, D.; Ustun, B.; Wittchen, H.U. The World Health Organization composite international diagnostic interview short-form (CIDI-SF). Int. J. Methods Psychiatr. Res. 1998, 7, 171-185. [CrossRef]

66. Kessler, R.C.; Üstün, T.B. The world mental health (WMH) survey initiative version of the world health organization (WHO) composite international diagnostic interview (CIDI). Int. J. Methods Psychiatr. Res. 2004, 13, 93-121. [CrossRef]

67. Kessler, R.C.; Abelson, J.; Demler, O.; Escobar, J.I.; Gibbon, M.; Guyer, M.E.; Howes, M.J.; Jin, R.; Vega, W.A.; Walters, E.E.; et al. Clinical calibration of DSM-IV diagnoses in the World Mental Health (WMH) version of the World Health Organization (WHO) Composite International Diagnostic Interview (WMH-CIDI). Int. J. Methods Psychiatr. Res. 2004, 13, 122-139. [CrossRef] 
68. Robins, L.N.; Wing, J.; Wittchen, H.U.; Helzer, J.E.; Babor, T.F.; Burke, J.; Farmer, A.; Jablenski, A.; Pickens, R.; Regier, D.A.; et al. The Composite International Diagnostic Interview: An epidemiologic instrument suitable for use in conjunction with different diagnostic systems and in different cultures. Arch. Gen. Psychiatry 1988, 45, 1069-1077. [CrossRef]

69. Haro, J.M.; Arbabzadeh-Bouchez, S.; Brugha, T.S.; De Girolamo, G.; Guyer, M.E.; Jin, R.; Lepine, J.P.; Mazzi, F.; Reneses, B.; Vilagut, G.; et al. Concordance of the Composite International Diagnostic Interview Version 3.0 (CIDI 3.0) with standardized clinical assessments in the WHO World Mental Health surveys. Int. J. Methods Psychiatr. Res. 2006, 15, 167-180. [CrossRef]

70. Wittchen, H.U.; Robins, L.N.; Cottler, L.B.; Sartorius, N.; Burke, J.D.; Regier, D. Cross-cultural feasibility, reliability and sources of variance of the Composite International Diagnostic Interview (CIDI). Br. J. Psychiatry 1991, 159, 645-653. [CrossRef]

71. Wittchen, H.U. Reliability and validity studies of the WHO-Composite International Diagnostic Interview (CIDI): A critical review. J. Psychiatr. Res. 1994, 28, 57-84. [CrossRef]

72. Assari, S.; Lankarani, M.M.; Moazen, B. Religious Beliefs May Reduce the Negative Effect of Psychiatric Disorders on Age of Onset of Suicidal Ideation among Blacks in the United States. Int. J. Prev. Med. 2012, 3, 358-364.

73. Hope, M.O.; Assari, S.; Cole-Lewis, Y.C.; Caldwell, C.H. Religious social support, discrimination, and psychiatric disorders among Black adolescents. Race Soc. Probl. 2017, 9, 102-114. [CrossRef]

74. Masnoon, N.; Shakib, S.; Kalisch-Ellett, L.; Caughey, G.E. What is polypharmacy? A systematic review of definitions. BMC Geriatr. 2017, 17, 230. [CrossRef] [PubMed]

75. Johnell, K.; Weitoft, G.R.; Fastbom, J. Sex differences in inappropriate drug use: A register-based study of over 600,000 older people. Ann. Pharmacother. 2009, 43, 1233-1238. [CrossRef] [PubMed]

76. Johnell, K.; Fastbom, J.; Rosén, M.; Leimanis, A. Inappropriate drug use in the elderly: A nationwide register-based study. Ann. Pharmacother. 2007, 41, 1243-1248. [CrossRef] [PubMed]

77. Al-Hashar, A.; Al Sinawi, H.; Al Mahrizi, A.; Al-Hatrushi, M. Prevalence and Covariates of Polypharmacy in Elderly Patients on Discharge from a Tertiary Care Hospital in Oman. Oman Med. J. 2016, 31, 421-425. [CrossRef] [PubMed]

78. Venturini, C.D.; Engroff, P.; Ely, L.S.; Zago, L.F.; Schroeter, G.; Gomes, I.; De Carli, G.A.; Morrone, F.B. Gender differences, polypharmacy, and potential pharmacological interactions in the elderly. Clinics (Sao Paulo) 2011, 66, 1867-1872. [PubMed]

79. Boucquemont, J.; Pai, A.L.; Dharnidharka, V.R.; Hebert, D.; Furth, S.L.; Foster, B.J. Gender differences in medication adherence among adolescent and young adult kidney transplant recipients. Transplantation 2018. [CrossRef] [PubMed]

80. Haider, S.I.; Johnell, K.; Weitoft, G.R.; Thorslund, M.; Fastbom, J. The influence of educational level on polypharmacy and inappropriate drug use: A register-based study of more than 600,000 older people. J. Am. Geriatr. Soc. 2009, 57, 62-69. [CrossRef]

81. Regitz-Zagrosek, V. Sex and gender differences in health. Science \& Society Series on Sex and Science. EMBO Rep. 2012, 13, 596-603. [CrossRef]

82. Bertakis, K.D.; Azari, R.; Helms, L.J.; Callahan, E.J.; Robbins, J.A. Gender differences in the utilization of health care services. J. Fam. Pract. 2000, 49, 147-152. [PubMed]

83. Vlahiotis, A.; Sedjo, R.; Cox, E.R.; Burroughs, T.E.; Rauchway, A.; Lich, R. Gender differences in self-reported symptom awareness and perceived ability to manage therapy with disease-modifying medication among commercially insured multiple sclerosis patients. J. Manag. Care Pharm. 2010, 16, 206-216. [CrossRef]

84. Braybrook, D.E.; Witty, K.R.; Robertson, S. Men and lung cancer: A review of the barriers and facilitators to male engagement in symptom reporting and screening. J. Men's Health. 2011, 8, 93-99. [CrossRef]

85. Galdas, P.M.; Cheater, F.; Marshall, P. Men and health help-seeking behaviour: Literature review. J. Adv. Nurs. 2005, 49, 616-623. [CrossRef] [PubMed]

86. Hammond, W.P.; Matthews, D.; Mohottige, D.; Agyemang, A.; Corbie-Smith, G. Masculinity, medical mistrust, and preventive health services delays among community-dwelling African-American men. J. Gen. Intern. Med. 2010, 25, 1300-1308. [CrossRef]

87. Addis, M.E.; Mahalik, J.R. Men, masculinity, and the contexts of help seeking. Am. Psychol. 2003, 58, 5-14. [CrossRef] [PubMed] 
88. Murtagh, K.N.; Hubert, H.B. Gender differences in physical disability among an elderly cohort. Am. J. Public Health 2004, 94, 1406-1411. [CrossRef]

89. Hawthorne, A.B.; Rubin, G.; Ghosh, S. Review article: Medication non-adherence in ulcerative colitis-Strategies to improve adherence with mesalazine and other maintenance therapies. Aliment. Pharmacol. Ther. 2008, 27, 1157-1166. [CrossRef]

90. Courtenay, W.H. Constructions of masculinity and their influence on men's well-being: A theory of gender and health. Soc. Sci. Med. 2000, 50, 1385-1401. [CrossRef]

91. Gijsber van Wijk, C.M.T.; Kolk, A.M.; van den Bosch, W.J.H.M.; van den Hoogen, H.J. Male and female morbidity in general practice: The nature of sex differences. Soc. Sci. Med. 1992, 35, 665-678. [CrossRef]

92. Suominen-Taipale, A.L.; Martelin, T.; Koskinen, S.; Holmen, J.; Johnsen, R. Gender differences in health care use among the elderly population in areas of Norway and Finland. A cross-sectional analysis based on the HUNT study and the FINRISK Senior Survey. BMC Health Serv. Res. 2006, 6, 110. [CrossRef] [PubMed]

93. Hatzfeld, J.J.; LaVeist, T.A.; Gaston-Johansson, F.G. Peer Reviewed: Racial/Ethnic Disparities in the Prevalence of Selected Chronic Diseases Among US Air Force Members, 2008. Prev. Chronic Dis. 2012, 9, E112. [CrossRef]

94. Haider, S.I.; Johnell, K.; Thorslund, M.; Fastbom, J. Analysis of the association between polypharmacy and socioeconomic position among elderly aged $>$ or $=77$ years in Sweden. Clin. Ther. 2008, 30, 419-427. [CrossRef] [PubMed]

95. Okoro, C.A.; Strine, T.W.; Young, S.L.; Balluz, L.S.; Mokdad, A.H. Access to health care among older adults and receipt of preventive services. Results from the Behavioral Risk Factor Surveillance System, 2002. Prev. Med. 2005, 40, 337-343. [CrossRef]

96. Farrell, B.; Shamji, S.; Monahan, A.; French Merkley, V. Reducing polypharmacy in the elderly: Cases to help you "rock the boat". Can. Pharm. J. 2013, 146, 243-244. [CrossRef]

97. Cooper, J.A.; Cadogan, C.A.; Patterson, S.M.; Kerse, N.; Bradley, M.C.; Ryan, C.; Hughes, C.M. Interventions to improve the appropriate use of polypharmacy in older people: A Cochrane systematic review. BMJ Open 2015, 5, e009235. [CrossRef] [PubMed]

98. Johansson, T.; Abuzahra, M.E.; Keller, S.; Mann, E.; Faller, B.; Sommerauer, C.; Höck, J.; Löffler, C.; Köchling, A.; Schuler, J.; et al. Impact of strategies to reduce polypharmacy on clinically relevant endpoints: A systematic review and meta-analysis. Br. J. Clin. Pharmacol. 2016, 532-548. [CrossRef]

99. Hajjar, E.R.; Cafiero, A.C.; Hanlon, J.T. Polypharmacy in elderly patients. Am. J. Geriatr. Pharmacother. 2007, 5, 345-351. [CrossRef] [PubMed]

100. Assari, S.; Bazargan, M. Polypharmacy and Psychological Distress May Be Associated in African American Adults. Pharmacy 2019, 7, 14. [CrossRef] [PubMed] 